Comparative Biochemistry and Physiology Part D: Genomics and Proteomics

Volume 2, Issue 1, March 2007, Pages 74-83

http://dx.doi.org/10.1016/i.cbd.2006.12.002

(c) 2006 Elsevier Inc. All rights reserved
Archimer, archive institutionnelle de l'Ifremer http://www.ifremer.fr/docelec/

\title{
Molecular characterisation of prolactin and analysis of extrapituitary expression in the European sea bass Dicentrarchus labrax under various salinity conditions
}

\author{
I. Boutet ${ }^{a,{ }^{\star}}$, C. Lorin-Nebel ${ }^{b}$, J. De Lorgeril, B. Guinand
}

\begin{abstract}
Laboratoire Génome Populations Interaction Adaptation, UMR CNRS IFREMER 5171, Université de Montpellier 2, Place Eugène Bataillon, 34095 MONTPELLIER cedex 5, FRANCE.
\end{abstract}

a present address: UMR CNRS 7144 Adaptation et Diversité en Milieu Marin, Evolution et Génétiques des Populations Marines, Station Biologique de Roscoff, Place Georges Tessier, 29680 Roscoff, France.

b present address : Department of Anesthesiology, Vanderbilt University Medical Center, Nashville, TN 37232, USA

*: Corresponding author :boutet@sb-roscoff.fr

\begin{abstract}
:
Although prolactin has been demonstrated to be the main hormone involved in adaptation to dilute media in several freshwater teleosts, few studies have been conducted in marine teleosts. In the Mediterranean, the sea bass Dicentrarchus labrax inhabits environments ranging from the open sea to coastal lagoons, where salinity varies greatly. We characterised the prolactin ( $p r l)$ gene and analysed its expression in two organs (gill and intestine) in D. labrax acclimated to either freshwater or seawater. A $2819 \mathrm{bp}$ long sequence encompassing the $\mathrm{prl}$ gene and a part (282 bp) of the promoter were identified, and these comprised 5 coding exons separated by 4 introns. Prolactin was similarly expressed in fresh- and seawater adapted fish, although expression in gills was significantly greater than in the intestine. Nonetheless, individuals unable to successfully regulate osmotic balance in freshwater presented overall low expression rates. Results are discussed according to the mechanism of sea bass adaptation in the wild and to their life cycle between open sea and lagoons. Finally, a phylogenetic analysis indicated that teleosts are not branched according to their life-history features (e.g. seawater vs. freshwater habitats), and no signature of positive selection was detected across the phylogeny of the $\mathrm{prl}$ gene in teleosts.
\end{abstract}

Keywords: Dicentrarchus labrax; Gill; Intestine; Osmoregulation; mRNA expression; Phylogenetic analysis; Prolactin 


\section{Introduction}

Prolactin (PRL) is a member of a family of structurally similar proteins classified as group I of helix bundle protein hormones (Freeman et al., 2000), which includes growth hormone and somatolactin in teleost fish, as well as placental lactogen in mammals. PRL, a pituitary hormone, is ubiquitous and has almost 300 recognized functions in vertebrates (reviews in Bole-Feysot et al., 1998), that include: (1) water and electrolyte balance, (2) growth and development, (3) metabolism, (4) behaviour, (5) reproduction, and (6) immunoregulation and protection (Bole-Feysot et al., 1998). Pickford and Phillips (1959) demonstrated that PRL was involved in freshwater adaptation by the killifish Fundulus heteroclitus. Numerous subsequent studies investigated the role of PRL in osmoregulation, and it is now generally accepted that PRL plays an important role in water balance, especially in freshwater where it prevents both diffusive ion loss and osmotic water uptake (McCormick, 2001; Hirose et al. 2003).

The gills, intestine and kidney have been shown to be the main sites of osmoregulation in teleosts (reviews in Evans et al., 1999; Marshall, 2003) and the osmoregulatory actions of PRL in these organs differs markedly amongst species (Bœuf et al., 1994; Eckert et al., 2001; Kelly et al., 1999; Leena and Oommen, 2000; Madsen et al., 1997; Seidelin and Madsen, 1997; Shepherd et al., 1997). It is well known that PRL receptors are present in these organs, indicating that these are the sites of PRL action (Lee et al., 2006). However, the prl gene has also been shown to be expressed in the liver, intestine and gonads of the gilthead sea bream (Sparus auratus) (Santos et al., 1999), as well as in the liver, kidney, spleen, gill, muscle, gonads and brain of the goldfish (Carassius auratus) (Imaoka et al., 2000). According to Santos et al. (1999), prl gene expression in tissues other than the adenohypophysis can reflect regulatory mechanisms that are different than those for the pituitary gene. Hence, the function of ectopic PRL remains to be elucidated. As complete gene sequences are potentially involved in gene regulation and expression through, e.g., transcription slippage or alternative mRNA splicing, accumulating data both in coding and non-coding regions is important to further understand how prl genes have evolved in teleosts.

Because of its role in freshwater adaptation, interest in the role of PRL in marine teleosts is much more recent (e.g., Doliana et al., 1994; Kelly et al., 1999; Santos et al., 1999; Astola et al., 2003, and references therein). However, marine species generally offer opportunities for comparative studies of gene expression with freshwater species. They also provide good models to study variation in PRL expression because ecophases of some species 
1 may exploit different salinity environments, ranging from seawater to freshwater, across their 2 life-cycle. This might imply distinct patterns of gene expression and/or gene regulation in osmoregulatory organs during the course of development, which might reveal ecological requirements of species at a specific stage. The European sea-bass Dicentrarchus labrax (Perciformes; Moronidae) is a marine teleost whose adults tolerate salinities ranging from freshwater to hypersaline seawater (Jensen et al., 1998). In the wild, some populations move seasonally between the open sea and lagoons/estuaries or even migrate up rivers to complete freshwater (Barnabé, 1976; Kelley, 1988). Saillant et al. (2003) further demonstrated that sea bass juveniles have a low saline preferendum (15\% compared to $37 \%$ in seawater) that corresponds to the conditions they may encounter during their juvenile ecophase in Mediterranean lagoons. Acclimation of sea-bass to freshwater has been performed in several studies (e.g. Venturini et al., 1992). However, in most studies, the freshwater challenge resulted in differential mortalities within the sea-bass populations (Dendrinos and Thorpe, 1985; Allegrucci et al., 1994; Pickett and Pawson, 1994; Jensen et al., 1998; Eroldogan and Kumlu, 2002; Nebel et al., 2005), a fact which probably results from an osmoregulatory deficiency of some sea-bass, as demonstrated by blood osmolality measurements and osmoregulatory organ analyses (Nebel et al., 2005). Moreover, PRL release is associated with changes in blood osmolalities in a closely related species, the hybrid striped bass (Morone saxatilis) (Jackson et al., 2005).

In the current study, we characterise the complete sequence of the prl gene of D. labrax. The study then study focused upon i) the expression patterns of the prl gene in the main osmoregulatory tissues in seawater acclimated sea-bass, and in fish successfully and unsuccessfully adapted to freshwater, and ii) the possible correlations between PRL expression and the natural distribution of sea-bass populations between brackish (lagoons) and sea-water habitats. Finally, by documenting sequence polymorphisms in both coding and non-coding regions of this gene, we propose a phylogeny of the prolactin ( prl) gene in teleosts.

\section{Materials and methods}

\subsection{Biological samples}


Tissue samples (dorsal fin and muscle) of seven individuals of European sea bass ( $D$. labrax) were obtained from the IFREMER centre (Institut Français de Recherche pour l'Exploitation de la Mer) located at Palavas les Flots (Hérault, France). Fish were adult spawners (4 females, 3 males) collected in the wild, then reared in common garden environment and used for hatchery production of larvae and juveniles. Those samples were used to investigate sea bass $\mathrm{prl}$ gene organisation.

In parallel, two-month old sea bass juveniles (both male and female sea bass; $20 \pm 1.5 \mathrm{~g}$; 3.8-5.7cm) obtained from the sea farm 'Poissons du Soleil' (Balaruc, Hérault, France) were acclimated in recirculating $20^{\circ} \mathrm{C}$ saltwater (10\%) under natural photoperiod before experimentation (during 2 weeks). Then, they were progressively acclimated to freshwater ( $n=250 ; 0.5 \%$, composition in mEq. $l^{-1}: 0.12 \mathrm{Na}^{+}, 0.04 \mathrm{~K}^{+}, 5.70 \mathrm{Ca}^{2+}, 0.29 \mathrm{Mg}^{2+}, 0.98 \mathrm{Cl}^{-}$, $\left.0.06 \mathrm{NO}_{3}{ }^{-}, 0.61 \mathrm{SO}_{4}{ }^{2-}\right)$ and seawater $(n=250 ; 32 \%$, renewed filtered seawater from the Thau lagoon) during a 3 week period with salinity steps of about 1 to $2 \%$ per day in April 2004. Sea bass categorized as unsuccessfully adapted to freshwater (UF) appeared one week after the beginning of the experiment and during a period of about two weeks. They presented abnormal behaviour (e.g., swimming out of the shoal, with little or no response to external disturbance), and died around $48 \mathrm{~h}$ after such behaviours were recorded. UF were collected daily, immediately dissected, and stored at $-80^{\circ} \mathrm{C}$ until studied. Among freshwater acclimated fish, $26 \%$ of the sea bass was recorded as UF. During and after the occurrence of UF individuals, the juveniles successfully adapted to freshwater (FW; $n=5)$ and seawater (SW; $n=5)$ were collected, dissected and intestine and gill tissues were sampled and stored at $-80^{\circ} \mathrm{C}$ until used. A low mortality rate of $1-2 \%$ and $5 \%$ was recorded in the SW and FW fish, respectively, during the whole experiment. The animals used in these experiments were simultaneously studied for physiological aspects (i.e., osmotic variables, morphology of urinary system, $\mathrm{Na}^{+} / \mathrm{K}^{+}$-ATPase localisation) (Nebel et al., 2005) and for transcriptomic variables (suppression subtractive hybridisation and mRNA expression) (Boutet et al., 2006).

Wild juveniles sea bass (1+, M. Cantou, Innovaqua, Sète; pers. comm.) were collected in December 2004 from the Mediterranean Sea $\left(35 \%\right.$; $\approx 11^{\circ} \mathrm{C}$; collected about $3 \mathrm{~km}$ offshore; $n=5$; Hérault, France) and from the Ingril Lagoon $\left(28.5 \%\right.$ at collection time; $\approx 5^{\circ} \mathrm{C} ; n=5$; Hérault, France). If salinity is roughly constant in the sea across the year, data have shown that salinity may vary from 3.5\% up to 41\% in the Ingril Lagoon (2004 survey; Syndicat Intercommunal des Etangs Littoraux, pers. comm.). All individuals were dissected and intestine and gill tissues were collected in tubes and stored at $-80^{\circ} \mathrm{C}$ until RNA extraction. 


\subsection{Characterisation of the prl gene in D. labrax}

Genomic DNA was extracted from the muscle of a single individual using a standard phenol/chloroform/isoamyl alcohol (25:24:1) extraction method. Primers used for amplification of $\mathrm{prl}$ gene were designed according to the available D. labrax sequence of prl (X78723; Doliana et al., 1994). By comparison with sea bream S. auratus (AJ509807) prl gene structure, we designed ten primers (forward and reverse) in each exon named PRL 1F/1R, PRL 2F/2R, PRL 3F/3R, PRL 4F/4R, PRL 5R (Fig. 1). The primer sequence is shown in Table 1. Amplification of the gene itself was carried out using primer combinations as follows: PRL 1F-PRL 2R, PRL 2F-PRL 3R, PRL 3F-PRL 4R, PRL 4F-PRL 5R. The reaction mixture contained 100ng of genomic DNA, 1X UptiTherm DNA polymerase buffer, $2 \mathrm{mM}$ $\mathrm{MgCl}_{2}, 100 \mu \mathrm{M}$ dNTPs, 20pmol of each primer and $1 \mathrm{U}$ of UptiTherm DNA polymerase (Interchim, Montluçon, France) in a 50 $\mu 1$-final volume and was submitted to amplification cycles as follows: one cycle at $95^{\circ} \mathrm{C}$ for $5 \mathrm{mn}$, one cycle at $58^{\circ} \mathrm{C}$ for $2 \mathrm{~min}$, one cycle at $72^{\circ} \mathrm{C}$ for $2 \mathrm{~min} 30,35$ cycles at $95^{\circ} \mathrm{C}$ for $30 \mathrm{~s}, 58^{\circ} \mathrm{C}$ for $30 \mathrm{~s}, 72^{\circ} \mathrm{C}$ for $2 \mathrm{~min}$ and a final elongation step at $72^{\circ} \mathrm{C}$ for $15 \mathrm{~min}$. We also amplified prl promoter region by using a method derived from GenomeWalker (digestion of genomic DNA, adapter ligation, cloning of the resulting product, PCR amplification by using adapter specific primers and prl reverse primers PRL 2R and PRL 1R for first and nested PCR, respectively). PCR products were electrophoresed on $1.5 \% 0.5 \mathrm{X}$ TBE agarose gel and after ethidium bromide staining, they were visualised under UV. Agarose bands correspondig to each primer combination were excised from the gel, purified using QIAEX II (Qiagen, Hilden, Germany), ligated into pGEM-T vector (Promega, Madison, WI, USA), transformed in Esherichia coli DH5 $\alpha$ competent cells and the alkaline lysis minipreparations were sequenced (MWG-Biotech AG, Ebersberg, Germany).

\subsection{Phylogenetic analysis}

In order to compare the sequence of the prl gene of the sea bass, we screened data bases (GenBank) for available sequences in teleosts. We only considered species for which nucleotide sequences were available. We partitioned sequences of available species as species with prl gene sequencing of exons and introns ( $N=5$; C. auratus [AY662676]; Cyprinus carpio [X52881]; Ictalurus punctatus [AF267990]; Oreochromis mossambicus [X92380] and S. auratus [AJ509807]), and species for which only cDNA were available ( $N=16$; Anguilla anguilla [X69149]; Anguilla japonica [AY158009]; Coregonus autumnalis [Z23114]; 
1 Cyprinus carpio [X12543]; Danio rerio [NM_181437]; D. labrax [X78723]; Epinephelus coioides [AY513648]; Hypophthalmichthys molitrix [X61052]; Hypophthalmichthys nobilis [X61049]; Oncorhynchus tshawytscha [M36267]; Oncorhynchus keta [D00249 and X64036]; Oncorhynchus mykiss [M24738]; Oreochromis niloticus [A07820]; Paralichthys olivaceus [AF047616]; Perca flavescens [AY332491]; Salmo salar [X84787], and Tetraodon nigroviridis [AY374505]). After preliminary analyses and alignment, we did not include sequences that presented rigorously similar cDNAs within species, including D. rerio, E. coioides, and S. aurata. In such cases, we generally reported accession numbers of the most recent submission to GenBank. Sequences with two distinct cDNAs were considered separately in two species (C. carpio and O. keta). For consistency, two available sequences, containing only partial cDNAs were not included in the analysis (Odontesthes bonariensis [AY323200]; Periophtalmus modestus [AB089194]).

Sequences were aligned using BioEdit v. 5.0.9. We used the software Mega v. 2.1 (Kumar et al., 2001) to produce one unrooted neighbor-joining (NJ) phylogeny of available prl gene coding-sequences. Maximum-likelihood and parsimony methods reported identical tree topologies and were not reported here. Once alignment and NJ tree were available, we computed maximum-likelihood computations of the global $\mathrm{dN} / \mathrm{dS}$ ratio (or $\omega_{0}$ ), then searched for amino-acid sites potentially undergoing positive selection along the $p r l$ gene. Significance of single amino-acid $\mathrm{dN} / \mathrm{dS}$ was investigated using the FEL (fixed-effect likelihood) method, a derivation of the single likelihood ancestor counting method described in Kosakovsky-Pond and Frost (2005a; as one implementation of the classical Suzuki-Gojobori method [Suzuki and Gojobori, 1999]). The FEL results was designed for low numbers of sequences $(<100)$, and was shown less conservative than other methods (Kosakovsky-Pond and Frost, 2005a). The selected nucleotide model was the standard HKY85 model (Hasegawa et al., 1985). We further use the genetic algorithm (GA) approach proposed by Kosakovsky-Pond and Frost (2005b) to search for partition of tree branches which evolve under different selective pressures $\left(\omega_{t}\right)$ values. The analysis finds the best partitioning of branches, estimates modelaveraged probabilities of observing positive selection at any given branch, tabulates inferred probability distributions of selective pressures at any branch, and computes model-averaged probabilities of any two branches having the same $\omega_{l}(\mathrm{dN} / \mathrm{dS})$. This genetic algorithm approach assigned lineages in a phylogeny to a fixed number of different site classes, $\omega_{l}$. Number of $\omega_{l}$ may vary from one ratio often called the global model [or model $\mathrm{M}_{0}$ ], until the local, free ratio model where each node in the phylogeny might evolve under a given selective 
1 regime. The GA approach allowed variable selection pressure without a priori specification of

particular lineages. The best number of site classes $\omega_{l}$ was based on inspection of Akaike information criterion (AIC), and the best-fitting model was selected using a ShimodairaHasegawa test (10,000 replicates; Shimodaira and Hasegawa 1999), using the difference in AIC, rather than the difference in log-likelihoods, to compare models with different numbers of parameters. All analyses including tool for selecting the best model of nucleotide substitution were performed in a maximum-likelihood framework using the web-based resource Datamonkey implemented at www.datamonkey.org (Kosakovsky-Pond and Frost 2005c), where more details can be found. The initial significance level of analysis was set to $\alpha=0.05$. We performed such analyses using both the full coding sequences available (i.e. representing the prohormone), and using only sequences corresponding to the final hormone after deletion of nucleotides identified in the coding of the signal peptide.

\subsection{Expression analysis of PRL in extrapituitary organs}

Analyses by semi-quantitative RT-PCR: Total RNA was extracted from the gills and intestine tissues of sea bass from all samples collected (experimental individuals: UF, FW, and SW; Mediterranean Sea and lagoon wild individuals, $n=5$ each) using Trizol (Invitrogen, Carlsbad, CA, USA) according to the manufacturer's instructions. Ten $\mu \mathrm{g}$ of total RNA was submitted to reverse transcription using oligo dT anchor primer (5'-GAC CAC GCG TAT CGA TGT CGA $\mathrm{CT}_{(16)} \mathrm{V}-3^{\prime}$ ') and M-MLV reverse transcriptase (Promega). The amplification of PRL was performed by using $1 \mu 1$ of 1:10 diluted products in $2 \mathrm{mM} \mathrm{MgCl}_{2}$ and 10 pmol of each primer PRL 2F and PRL 5R (Table 1). Amplification cycles were conducted as follows: $2 \mathrm{~min}$ at $94^{\circ} \mathrm{C}, 2 \mathrm{~min}$ at $57^{\circ} \mathrm{C}, 1 \mathrm{~min}$ at $72^{\circ} \mathrm{C}, 35$ cycles at $94^{\circ} \mathrm{C}$ for $20 \mathrm{sec}, 57^{\circ} \mathrm{C}$ for $30 \mathrm{sec}, 72^{\circ} \mathrm{C}$ for $40 \mathrm{sec}$, and a final elongation at $72^{\circ} \mathrm{C}$ for $7 \mathrm{~min}$. $28 \mathrm{~S}$ ribosomal DNA was used as a PCR internal control under the same conditions with primers sense 5'-CTC AGT AGC GGC GAG CGA AGA GGG AAG-3' and antisense 5'-AGG TAC TTG TCG ACT ATC GGT CTC GTG-3' (25 PCR cycles were used in order to avoid band intensity saturation for optical determination). For semi-quantitative RT-PCR, the number of PCR cycles (20-45) was optimised to analyse expression in exponential phase of PCR. The resulting PCR products were electrophoresed in a $0.5 \mathrm{X} \mathrm{TBE} / 1.5 \%$ agarose gel, and visualised with UV after BET coloration. Quantification of band intensities was measured by using Gene Profiler v. 4.03 Software (Scanalytics Inc.). A non-parametric Kruskall-Wallis test was used to compare the expression between gills and intestine. A Mann-Whitney $U$-test was used to compare results 
among fish categories within each organ. Statistical analyses were performed by using Statistica software v. 6.0.

\section{Results}

\subsection{Organisation of the sea bass prl gene}

The sequence of the $p r l$ gene contains 5 coding exons of 43,113,108, $183 \mathrm{bp}$ for exons 1 to 4 , respectively. Because of the design of primer PRL 5R within the last exon (Fig. 1), the full length of the fifth exon is truncated and we amplified only 179bp (Table 2). Considering the available Genbank sequence (X78723; Doliana et al., 1994) used to design primer PRL $5 \mathrm{R}$, the full length of the fifth exon was expected to be $189 \mathrm{bp}$. We only identified 208 aminoacids (aa) (Fig. 2) instead of the 212 aa expected from Doliana et al. (1994). Despite this difference, derived from our amplification strategy for the prl gene, it was clear that the observed length variations in the teleost $p r l$ gene were greater amongst introns than amongst exons. Results are summarised in Table 2. In D. labrax, all the intron borders of PRL start and end with the consensus GT and AG splicing signals (Fig. 2). Further to the gene sequence, we also amplified a small portion (282 bp) of the promoter, where one TATA box (TATAAAA) and a pituitary specific factor 1 binding site (Pit-1, TAACCAT) were found (Fig 2). We did not identify polymorphisms (either at synonymous or non-synonymous positions) in coding regions of the prl gene in the seven individuals (wild adult spawners).

\subsection{Phylogenetic analysis}

Twenty-four PRL sequences that spanned several fish groups (Salmoniforms, Anguilliforms, Siluriforms, Cypriniforms, and Percomorphs) were selected for analysis. Phylogenetic trees obtained, either with or without the peptide signal sequence, were characterised by a clear separation of fish species according to their phylogenetic groups, but not by their salinity tolerance (freshwater vs. seawater habitats) (Fig. 3). Note that previous prl sequence reported by Doliana et al. (1994) slightly differed (two mutations) from the one reported in this study.

Because of its shorter length, we excluded the sequence of $H$. molitrix when investigating patterns of positive selection at amino-acid sites across the various prl 
1 sequences. The global $\mathrm{dN} / \mathrm{dS}$ ratio was estimated to 0.243 for the full length sequence, and 20.248 when deleting the sequence of the signal peptide, indicating strong stabilizing selection over this gene. No single amino-acid site was found positively selected across the gene sequence at the $5 \%$ level, against 89 significantly negatively selected sites. Relaxing significance of analyses to $\alpha=0.10$ indicated that only three sites could be affected by positive selection (105 by stabilizing selection) across the prl gene, but two of them where found in the signal peptide, and only one in the active part of the gene (site 133; $P=0.078$ ). For this last amino-acid, further analyses revealed a clear change for percomorphs (except in T. nigroviridis; Fig. 3) compared to all other species. In all percomorps this amino-acid was one alanine (GCA), or one valine (GTA) for Oreochromis species. For all other species including the basal percomorph $T$. nigroviridis, a cystidine was recorded at the first position of the codon. Nevertheless, no branch of the tree reported significant dN/dS $\left(\omega_{t}\right)$ according to the best fitting GA model. This best fitting GA model possessed three distinct $\omega_{t}\left(\omega_{0}=0.009\right.$, $\left.\omega_{1}=0.127, \omega_{2}=0.371 ; \mathrm{AIC}=10,831\right)$. This model significantly improved the global model with only one $\omega(\mathrm{AIC}=10,907$; significant Shimadaira and Hasegawa test: $P<0.001)$, as well as the model with two $\omega_{l}(\mathrm{AIC}=10,854 ; P<0.01)$. Results were similar when removing the signal peptide from initial sequences, including marginal significance of site 133 as a positively selected site $(P=0.088)$, and a best fitting GA model with three $\omega_{l}$ 's (details not given).

\subsection{Expression analysis of PRL in the gills and the intestine}

Expression analysis of $\mathrm{prl}$ in the gills and intestine of D. labrax following acclimation to the two salinities, and from the natural populations, demonstrated an expression pattern that was dependent upon both condition and tissue (Fig. 4). Expression was significantly higher in gills than in the intestine for all SW, FW and Lag samples $(P<0.05$; Fig. 4A, B), although not in the UF and Sea samples ( $P=0.445$ and $P=0.537$, respectively).

In sea-bass submitted to an experimental salinity transfer, a high PRL expression was recorded in gills of $\mathrm{FW}$ and $\mathrm{SW}$ individuals (Fig. 4A). In the UF gills, however, a significantly lower expression was recorded (Fig. 4A). In the intestine of the experimentally acclimated sea-bass, no significant PRL expression was recorded in UF compared to SW and FW (Fig. 4B). When comparing experimental (SW, FW, UF) to wild-caught individuals (Sea, Lag), a significantly higher PRL expression was recorded in the gills and intestine of the wild 
1 animals compared to UF fish (Fig. 4A, B). In wild sea bass, PRL expression was found marginally significant between lagoon and sea samples (Mann-Whitney test: $U=20, P=$ $0.075)$, in gills, but not in intestine $(U=15, P=0.345)$. One investigation of prl mRNA expression by real-time PCR rather than by semi-quantitative PCR indicated the same pattern of expression in wild-caught individuals and reached the same conclusions (data not shown). This proved results of semi-quantitative PCR reliable. No similar real-time PCR analyses were conducted on experimentally-exposed fish.

\section{Discussion}

\subsection{Prl gene structure of sea bass and phylogenetic relationships across teleost}

We provide the first characterisation of the prolactin gene in the European sea bass, $D$. labrax; a gene that encodes a hormone involved in freshwater adaptation in fishes (Burden, 1956; McCormick, 2001). To date, only the coding sequence of the prl gene has been reported (Doliana et al., 1994). Although our strategy did not provide full amplification of prl gene (10 bp / 4 aa were missing), we demonstrated that this gene in sea bass was interrupted by 4 introns, as has been described in other fish species (Chen et al., 1991; Watanabe et al., 1992; Swennen et al., 1992; Astola et al., 2003), and mammals (Forsyth and Wallis, 2002). Among available $\mathrm{prl}$ gene sequences of teleosts (C. carpio, I. punctatus, O. mossambicus and S. auratus), we observed a variability both in exon and intron lengths. We also identified a pituitary-specific factor Pit-1 (TAACCAT; general motif ((A/T) $\left.)_{3} \mathrm{NCAT}\right)$ (Elsholtz et al., 1992; Yamada et al., 1993) in the promoter region of the prl gene of D. labrax. The prl promoter is known to contain multiple binding sites for the tissue-specific transcription factor Pit-1 (Nelson et al., 1988; Mangalam et al., 1989), and Pit-1 binding sites may contribute to both basal and hormonally regulated transcription (Iverson et al., 1990; Yan and Bancroft, 1991; Yan et al., 1991; Hoggard et al., 1991; Kim et al., 1993; Shepard et al., 1994). Astola et al. (2003) clearly assessed that Pit-1 binding sites regulate prolactin gene expression in the sea bream S. auratus. However, alignment of promoter sequences of S. auratus and D. labrax indicated that such a Pit-1 binding site were not homologous (-110 bp and -180 bp for sea bream and sea bass, respectively; results not shown).

Our analysis of available teleost $\mathrm{prl}$ sequences indicates that fish species are strictly clustered according to their phylogenetic groups (Fig. 3), but not to their ecology (i.e., salinity 
1 level of their habitat), as might be expected for a gene encoding a protein involved in 2 freshwater adaptation. Some freshwater species (P. flavescens or O. mossambicus) are in the same branch as marine species (S. auratus or D. labrax). The global dN/dS of prl coding sequence was low ( 0.24 with or without considering the signal peptide) and no amino-acid sites were found positively affected by selection at the $\alpha=0.05$ level. Methods assuming several levels of selection pressure $\left(\omega_{\mathrm{i}}\right)$ did not reported any tree branches (i.e. phylogenetic groups) for which positive selection could occur in subsets of phylogeny. Only three single sites - two located in the signal peptide and only one in the functional hormone - were found potentially affected by positive selection at the $\alpha=0.10$ level of significance ( $p$-values ranging from 0.053 to 0.078 ). The site located in the hormone (site $133 ; P=0.078$ ) indicated a possible selective change among percomorphs (first position of the codon is a guanine; except T. nigroviridis that is a basal percomorph), compared to other species including $T$. nigroviridis (first position of the codon is a cystidine). As the signal peptide is rapidly cleaved during transport to the lumen of endoplasmic reticulum, we consider that sites undergoing potential positive selection (sites 8 and $9 ; P$-values 0.066 and 0.053 , respectively) could results from possible misalignment of this far less conserved part of the gene, or of higher mutation rates that translated in biased results. Nevertheless, one interaction between cleaved prl's peptide signal and calmodulin, one efficient calcium-binding protein involved in numerous cellular functions including tissue osmoregulation (Fenwick 1989; Zaccone et al. 1989), has been reported (Martoglio et al. 1997). Functional properties of such cleaved elements should be evaluated further in teleosts. The results suggest that the prl gene is under strong stabilizing selection across fish lineages, but that a trend among most percomorphs and other groups should be further investigated by considering more sequences (Pie, 2006).

Accordingly, this further suggests that molecular features which may explain the distribution and life-history of teleosts (e.g. freshwater vs seawater; anadromous species vs catadromous species) are probably not closely related to $p r l$ sequences, but more probably to other features including, for example, the previously mentioned distribution and regulation of Pit-1 binding site; various features of the non-coding DNA (e.g. Wray et al., 2003; Li et al., 2004), and/or differential activation of the prolactin receptor in distinct osmoregulatory organs (see review in Power, 2005). Complementary analyses are necessary to validate the effective role of mRNA synthesis in extrapituitary organs (quantification of circulating PRL). 


\subsection{Prl expression in the gills and the intestine}

It has been demonstrated that pituitary PRL release is stimulated at low salinities in euryhaline species (Pickford and Phillips, 1959; Seale et al., 2002). In mammals, numerous extrapituitary tissues also synthesize PRL, and the full spectrum of PRL functions is not yet completely understood. It has been suggested that extrapituitary PRL may compensate, at least in part, for a deficiency in pituitary PRL (Ben-Jonathan et al., 1996). In non-mammalian vertebrates, $p r l$ gene expression at extrapituitary sites has only been shown in a few fish species (Santos et al., 1999; Yang et al., 1999; Imaoka et al., 2000; Zang et al., 2004; Sakamoto et al., 2005), and the role of the extrapituitary PRL is still unclear. In the mudskipper P. modestus, expression of PRL mRNA was higher in the gut of freshwater fish than in seawater animals, indicating a role in hyperosmoregulation (Sakamoto et al., 2005). Branchial and intestinal tissues were chosen for this study because of their roles in osmoregulation. Organs involved in osmoregulation have been shown to present large PRL receptor populations in fish (Manzon, 2002; Lee et al., 2006), indicating that such organs are the main targets for PRL action. In the current study, analysis of prl gene expression indicated a tissue-dependent difference whereby the gene was more expressed in the gills than in the intestine in SW, FW and Lag samples. Previous studies have reported tissue-dependent PRL gene expression in fish (Imaoka et al., 2000; Zhang et al., 2004). High levels of PRL expression have been recorded in the gills of the marine orange-spotted grouper Epinephelus coioides compared to the kidney, liver and blood cells (Zhang et al., 2004). In the goldfish, PRL expression was recorded in the ovary, testis, liver, kidney, spleen, gill, muscle and brain, in slightly lower abundance than in the pituitary (Imaoka et al., 2000). The relative abundance of the $p r l$ transcripts between extrapituitary organs and the pituitary has been shown to vary according to the species (Imaoka et al., 2000), and should be investigated in future studies in sea bass.

\subsection{Insights from experimental and wild caught fishes}

Despite low numbers of individuals, which may reduce the power of our statistical analysis, both experimental and wild individuals have been used in this study. Each kind of individual provided interesting insights into the osmoregulatory ability and the ecology of sea bass. 
In the experimentally exposed SW and FW sea bass, prl gene expression in gills was higher than in the intestine. This suggests a role for locally synthesised PRL in osmoregulation via the regulation of $\mathrm{Na}^{+} / \mathrm{K}^{+}$-ATPase activity, chloride cell morphology, distribution and number in gill tissue. However, no significant difference has been recorded between SW and FW samples, which may rule out the exclusive role of extrapituitarysynthesised PRL in hyper-osmoregulation. In UF gills, a significantly lower PRL expression was measured. A previous study reported that these same individuals were not able to maintain their hydro-mineral balance in freshwater (Nebel et al., 2005). The approximately 5 fold decrease in local prl expression might result in the decreased blood osmolality recorded in the UF, as is the case in hypophysectomised striped bass, M. saxatilis (Jackson et al., 2005). PRL has also been shown to decrease chloride cell number, size and active ion transport in the tilapia (Foskett et al., 1982; Herndon et al., 1991). The gills of UF were characterised by a significantly higher number of lamellar chloride cells with higher specific $\mathrm{Na}^{+} / \mathrm{K}^{+}$-ATPase activity than FW fish (Nebel et al., 2005). Given the low prl expression in UF gills, the decrease in locally synthesised PRL might affect chloride cell number and $\mathrm{Na}^{+} / \mathrm{K}^{+}$-ATPase activity, but the effect of PRL on these cells remains to be investigated. Regarding the intestine, the prl expression results also indicated a condition-dependent expression pattern. As for the gills, the UF sea bass presented low expression, significantly lower than in the Sea and Lag samples. The low expression in gill and intestine of UF fish is particularly striking. These individuals are characterised by an abnormal behaviour after longterm freshwater exposure (Nebel et al., 2005). The physiological dysfunctions recorded in UF probably led to the death of the animals. Our results indicate a very low or a lack of PRL expression in UF fish tissues, in accordance with their osmoregulatory failure in freshwater.

Secondly, in wild fish, the marine individuals presented a level of gill prl expression close to the expression of SW and FW fish, whereas the lagoon-caught sea bass showed almost 2.5-fold higher expression. This difference was not statistically significant $(P=0.075)$, but due to the low number of fish used in each category (Sea or Lag; Fig. 4A), such a difference should be investigated further. A closer look at each individual's relative PRL expression in gills from lagoon samples, from both the semi-quantitative RT-PCR or real-time PCR (not shown) approaches, suggested coexistence of individuals with either low (i.e., levels similar to UF) or high $\mathrm{prl}$ expression. This variability in relative PRL expression, which was only recorded in lagoon individuals, may originate from the physiological heterogeneity of fish moving between the lagoon from the sea, or confronted with various salinities within the lagoon itself. The lagoons are characterised by a highly variable medium, where salinity 
1 changes considerably throughout the year (from about $3.5 \%$ in January to $41 \%$ in

2 September 2004 for the Ingril Lagoon).

3

4

5

6

7

8

9

\section{Perspectives}

In euryhaline fish; osmoregulatory mechanisms following adaptation to different environmental salinities are known to be under the control of hormonal factors such as prolactin and cortisol. In euryhaline teleosts, these hormones increase in plasma levels usually within a few days after freshwater or seawater entry and seem to drive the osmoregulatory system in the appropriate direction. Differentially expressed proteins (Sakamoto et al., 2001; and references therein) may play a role for the subsequent survival of the fish, although changes in mRNA levels do not necessarily reflect different amounts of the encoded proteins. The expression pattern of prolactin mRNA in gill and intestine described in the present study, together with the mRNA variations described by Boutet et al. (2006) in the same animals and tissues, may provide convenient starting points from which to study the molecular basis of salinity adaptation in sea bass. A further step would be to address the question of how environmental factors trigger the differential expression of genes such as prl. Identification of regulatory polymorphisms would also be very important in understanding the basis for the inter-individual diversity in responses to salinity that have been observed in this species.

\section{Acknowledgements}

Authors would like to thank D. McKenzie, G. Charmantier, F. Bonhomme, M.D. Guezguez, B. Châtain and J. Chatagnon for support, as well as J. Picot at the Syndicat Intercommunal des Etangs Littoraux (Frontignan, France) for providing physico-chemical data for the Ingril lagoon in 2004, and M. Cantou (Innovaqua, SMEL, Sète) for providing the wild sea bass used in this study. Personnel at the 'Poissons du Soleil' seafarm at Balaruc, and from the IFREMER biological station at Palavas-les-Flots, are also gratefully acknowledged.

\section{References}


Allegrucci, G., Fortunato, C., Cataudella, S., Sbordoni, V., 1994. Acclimation to fresh water of the sea bass: evidence of selective mortality and allozyme genotypes. In: Beaumont A.R. (eds.), Genetics and Evolution of Marine Organisms. Chapman and Hall, London, pp. 486-502.

Astola, A., Ortiz, M., Calduch-Giner, J.A., Perez-Sanchez, J., Valdivia, M.M., 2003. Isolation of Sparus auratus prolactin gene and activity of the cis-acting regulatory elements. Gen. Comp. Endocrinol. 134, 57-61.

Barnabé, G., 1976. Contribution à la connaissance de la biologie du loup Dicentrarchus labrax (L.) (poisson Serranidae). Thèse Doct. Etat. Sci. Nat. USTL, Montpellier.

Ben-Jonathan, N., Mershon, J.L., Allen, D.L., Steinmetz, R.W., 1996. Extrapituitary prolactin: distribution, regulation, functions, and clinical aspects. Endocr. Rev. 17, 639669.

Boeuf, G., Marc, A.M., Prunet, P., Le Bail, P.Y., Smal, J., 1994. Stimulation of parr-smolt transformation by hormonal treatment in Atlantic salmon (Salmo salar L.). Aquaculture 121, 195-208.

Bole-Feysot, C., Goffin, V., Edery, M., Binart, N., Kelly, P.A., 1998. Prolactin (PRL) and its receptor: actions, signal transduction pathways and phenotypes observed in PRL receptor knockout mice. Endocr. Rev. 19, 225-268.

Boutet, I., Long Ky, C.L., Bonhomme, F., 2006. A transcriptomic approach of salinity response in the euryhalin teleost, Dicentrarchus labrax. Gene. In press.

Burden, C.E., 1956. The failure of hypophysectomized Fundulus heteroclitus to survive in freshwater. Biol. Bull. 110, 8-28.

Chen, H.T., Chiou, C.S., Chang, W.C., 1991. Cloning and characterization of the carp prolactin gene. Biochim. Biophys. Acta 1088, 315-318.

Dendrinos, P., Thorpe, J.P. 1985. Effects of reduced salinity on growth and body composition in the European bass Dicentrarchus labrax (L.). Aquaculture 49, 333-358.

Doliana, R., Argentini, C., Segat, D., Santarossa, P., Mucignat, M.T., Colombo, L., Bortolussi, M., 1994. The prolactin of European sea bass (Dicentrarchus labrax L.): cloning of cDNA and efficient expression in Escherichia coli. Biochem. Mol. Biol. Int. $33,1117-1126$.

Eckert, S.M., Yada, T., Shepherd, B.S., Stetson, M.H., Hirano, T., Grau, E.G., 2001. Hormonal control of osmoregulation in the channel catfish Ictalurus punctatus. Gen. Comp. Endocrinol. 122, 270-286. 
1 Elsholtz, H.P., Majumdar-Sonnylal, S., Xiong, F., Gong, Z., Hew, C.L., 1992. Phylogenetic specificity of prolactin gene expression with conservation of Pit-1 function. Mol. Endocrinol. 6, 515-522.

Eroldogan, O.T., Kumlu, M., 2002. Growth performance, body traits and fillet composition of the european sea bass (Dicentrarchus labrax) reared in various salinities and freshwater. Turk. J. Vet. Anim. Sci. 26, 993-1001.

Evans, D.H., Piermarini, P.M., Potts, W.T.W., 1999. Ionic transport in the fish gill epithelium. J. Exp. Biol. 283, 641-652.

Fenwick, J.C., 1989. Calcium exchange across fish gills. In Vertebrate Endocrinology: Fundamentals and Biomedical Implications, vol. 3 (ed. P. K. T. Pang and M. P. Schreibman), pp. 319-342. New York: Academic Press.Forsyth, I.A., Wallis, M., 2002. Growth Hormone and prolactin — molecular and functional evolution. J. Mammary Gland Biol. Neoplasia 7, 291-312.

Foskett, J.K., Machen, T.E., Bern, H.A. (1982). Chloride secretion and conductance of teleost opercular membrane: effects of prolactin. Am. J. Physiol. 242, R380-R389.

Freeman, M.E., Kanyicska, B., Lerant, A., Nagy, G., 2000. Prolactin: structure, function, and regulation of secretion. Physiol. Rev. 80, 1523-1631.

Hasegawa, M., Kishino, H., Yano, T., 1985. Dating the human-ape splitting by a molecular clock of mitochondrial DNA. J. Mol. Evol. 22: 160-174.

Herndon, T.M., McCormick, S.D., Bern, H.A., 1991. Effects of prolactin on chloride cells in opercular membrane of seawater-adapted tilapia, Gen. Comp. Endocrinol. 83, 283-289.

Hirose, S., Kaneko, T., Naito, N., Takei, Y., 2003. Molecular Biology of major components of chloride cells. Comp. Biochem. Physiol. 136B, 593-620.

Hoggard, N., Davis, J.R., Berwaer, M., Monget, P., Peers, B., Belayew, A., Martial, J.A., 1991. Pit-1 binding sequences permit calcium regulation of human prolactin gene expression. Mol. Endocrinol. 5, 1748-1754.

Imaoka, T., Matsuda, M., Mori, T., 2000. Extrapituitary expression of the prolactin gene in the goldfish, African clawed frog and mouse. Zool. Sci. 17, 791-796.

Iverson, R.A., Day, K.H., d'Emden, M., Day, R.N., Maurer, R.A., 1990. Clustered point mutation analysis of the rat prolactin promoter. Mol. Endocrinol. 4, 1564-1571.

Jackson, L.F., McCormick, S.D., Madsen, S.S., Swanson, P., Sullivan, C.V., 2005. Osmoregulatory effects of hypophysectomy and homologous prolactin replacement in hybrid striped bass. Comp. Biochem. Physiol. 140B, 211-218. 
Jensen, K., Madsen, S.S., Kristiansen, K., 1998. Osmoregulation and salinity effects on the expression and activity of $\mathrm{Na}^{+}, \mathrm{K}^{+}$-ATPase in the gills of European sea bass, Dicentrarchus labrax (L.). J. Exp. Zool. 282, 290-300.

Kelley, D.F., 1988. The importance of estuaries for sea bass, Dicentrarchus labrax (L.). J. Fish. Biol. 33, 25-33.

Kelly, S.P., Chow, I.N.K., Woo, N.Y.S., 1999. Effects of prolactin and growth hormone on strategies of hypoosmotic adaptation in a marine teleost, Sparus sarba. Gen. Comp. Endocrinol. 113, 9-22.

Kim, M.K., McClaskey, J.H., Bodenner, D.L., Weintraub, B.D., 1993. An AP-1-like factor and the pituitary-specific factor Pit-1 are both necessary to mediate hormonal induction of human thyrotropin beta gene expression. J. Biol. Chem. 268, 23366-23375.

Kosakovsky Pond, S.L., Frost, S.D.W., 2005a. Not so different after all: a comparison of methods for detecting amino-acid sites under selection. Mol. Biol. Evol. 22,1208-1222.

Kosakovsky Pond, S.L., Frost, S.D.W., 2005b. A genetic algorithm approach to detecting lineage-specific variation in selection pressure. Mol. Biol. Evol. 22, 478-485.

Kosakovsky Pond, S.L., Frost, S.D.W., 2005c. Datamonkey: rapid detection of selective pressure on individual sites of codon alignments. Bioinformatics 21, 2531-2533.

Kumar, S., Tamura, K., Jakobsen, I.B., Nei, M., 2001. MEGA2: molecular evolutionary genetics analysis software. Bioinformatics 17, 1244-1245.

Lee, K.M., Kaneko, T., Aida, K., 2006. Prolactin and prolactin receptor expressions in a marine teleost, pufferfish Takifugu rubripes. Gen. Comp. Endocrinol. 146, 318-328.

Leena, S., Oommen, O.V., 2000. Hormonal control on enzymes of osmoregulation in a teleost, Anabas testudineus (Bloch): An in vivo and in vitro study. Endocr. Res. 26, 169287.

Li, Y.C., Korol, A.B., Fahima, T., Nevo, E., 2004. Microsatellites within genes: structure, function, and evolution. Mol. Biol. Evol. 21, 991-1007.

Madsen, S.S., Nishioka, R.S., Bern, H.A., 1997. Prolactin antagonises seawater acclimation in the anadromous striped bass, Morone saxatilis. In: Kawashima S., Kikuyama, S. (Eds.), Advances in Comparative Endocrinology, Vol. 2. Monduzzi Editore, Italy. pp. 10111015.

Mangalam, H.J., Albert, V.R., Ingraham, H.A., Kapiloff, M., Wilson, L., Nelson, C., Elsholtz, H., Rosenfeld, M.G., 1989. A pituitary POU domain protein, Pit-1, activates both growth hormone and prolactin promoters transcriptionally. Genes Dev. 3, 946-958. 
1 Manzon, L.A., 2002. The role of prolactin in fish osmoregulation: a review. Gen. Comp. Endocrinol. 125, 291-310.

Marshall, W.S., 2003. Rapid regulation of $\mathrm{NaCl}$ secretion by estuarine teleost fish: coping strategies for short-duration freshwater exposures. Biochim. Biophys. Acta 1618, 95-105.

Martoglio, B., Graf, R., Dobberstein, B., 1997. Signal peptide fragments of preprolactin and HIV-1 p-gp160 interact with calmodulin. EMBO J. 16: 6636-45.

McCormick, S.D., 2001. Endocrine control of osmoregulation in teleost fish. Amer. Zool. 41, 781-794.

Nebel, C., Romestand, B., Nègre-Sadargues, G., Grousset, E., Aujoulat, F., Bacal, J., Bonhomme, F., Charmantier, G., 2005. Differential freshwater adaptation in juvenile seabass Dicentrarchus labrax : involvement of gills and urinary system. J. Exp. Biol.208: 3859-3871.

Nelson, C., Albert, V.R., Elsholtz, H.P., Lu, L.I., Rosenfeld, M.G., 1988. Activation of cellspecific expression of rat growth hormone and prolactin genes by a common transcription factor. Science 239, 1400-1405.

Pickett, G.D., Pawson, M.G., 1994. Biology and Ecology. In: Pitcher T.J. (Eds.), Sea Bass. Biology, Exploitation and Conservation. Chapman and Hall, London. pp. 9-146.

Pickford, G.E., Phillips, J.G., 1959. Prolactin, a factor in promoting survival of hypophysectomised killifish in fresh water. Science 130, 454-455.

Pie, M.R., 2006. The effect of phylogenetic uncertainty on the detection of positive Darwinian selection. Mol. Biol. Evol. 23: 2274-2278.

Power, D.M., 2005. Developmental ontogeny of prolactin and its receptor in fish. Gen. Comp. Endocrin. 142, 25-33.

Saitou, N., Nei, M., 1987. The neighbor-joining method - a new method for reconstructing phylogenetic trees. Mol. Biol. Evol. 4, 406-425.

Saillant, E., Fostier, A., Haffray, P., Menu, B., Chatain, B., 2003. Saline preferendum for the European sea bass, Dicentrarchus labrax, larvae and juveniles: effect of salinity on early development and sex determination. J. Exp. Mar. Biol. Ecol. 287, 103-117.

Sakamoto, T., Uchida, K., Yokota, S., 2001. Regulation of the ion-transporting mitochondrion-rich cell during adaptation of teleost fishes to different salinities. Zoolog. Sci. 18, 1163-1174.

Sakamoto, T., Amano, M., Hyodo, S., Moriyama, S., Takahashi, A., Kawauchi, H., Ando, M., 2005. Expression of prolactin-releasing peptide and prolactin in the euryhaline 
mudskippers (Periophthalmus modestus): prolactin-releasing peptide as a primary regulator of prolactin. J. Molec. Endocrin. 34, 825-834.

Santos, C.R., Brinca, L., Ingleton, P.M., Power, D.M., 1999. Cloning, expression, and tissue localisation of prolactin in adult sea bream (Sparus aurata). Gen. Comp. Endocrinol. 114, 57-66.

Seale, A.P., Riley, L.G., Leedom, T.A., Kajimura, S., Dores, R.M., Hirano, T., Grau, E.G., 2002. Effects of environmental osmolality on release of prolactin, growth hormone and ACTH from the tilapia pituitary. Gen. Comp. Endocrinol. 128, 91-101.

Seidelin, M., Madsen, S.S., 1997. Prolactin antagonizes the seawater-adaptive effect of cortisol and growth hormone in anadromous brown trout (Salmo trutta). Zool. Sci. 14, 249-256.

Shepard, A.R., Zhang, W., Eberhardt, N.L., 1994. Two CGTCA motifs and a GHF1/Pit1 binding site mediate cAMP-dependent protein kinase A regulation of human growth hormone gene expression in rat anterior pituitary GC cells. J. Biol. Chem. 269, 18041814.

Shepherd, B.S., Sakamoto, T., Nishioka, R.S., Richman, N.H.III., Mori, I., Madsen, S.S., Chen, T.T., Hirano, T., Bern, H.A., Grau, E.G., 1997. Somatotropic actions of the homologous growth hormone and prolactins in the euryhaline teleost, the tilapia, Oreochromis mossambicus. Proc. Natl. Acad. Sci. USA 94, 2068-2072.

Shimodaira, H., Hasegawa, M., 1999. Multiple comparisons of log-likelihoods with applications to phylogenetic inference. Mol. Biol. Evol. 16, 1114-1116.

Suzuki, Y., Gojobori, T., 1999. A method for detecting positive selection at single amino acid sites. Mol. Biol. Evol. 16, 1315-1328

Swennen, D., Poncelet, A.C., Sekkali, B., Rentier-Delrue, F., Martial, J.A., Belayew, A., 1992. Structure of the tilapia (Oreochromis mossambicus) prolactin I gene. DNA Cell Biol. 11, 673-684.

Venturini, G., Cataldi, E., Marino, G., Pucci, P., Garibaldi, L., Bronzi, P., Cataudella, S., 1992. Serum ions concentration and ATPase activity in gills, kidney and oesophagus of European sea bass (Dicentrarchus labrax, Pisces, Perciformes) during acclimation trials to fresh water. Comp. Biochem. Physiol. 103A, 451-454.

Watanabe, K., Igarashi, A., Noso, T., Chen, T.T., Durham, R.A., Kawauchi, H., 1992. Chemical identification of catfish growth hormone and prolactin. Mol. Mar. Biol. Biotechnol. 1, 239-249. 
1 Wray, G.A., Hahn, M.W., Abouheif, E., Balhoff, J.P., Pizer, M., Rockman, M.V., Romano, L.A., 2003. The evolution of transcriptional regulation in eukaryotes. Mol. Biol. Evol. 20, $1377-1419$.

Yamada, S., Hata J.I, Yamashita S., 1993. Molecular cloning of fish Pit-1 cDNA and its functional binding to promoter of gene expressed in the pituitary. J. Biol. Chem. 268, 24361-24366.

Yan, G.Z., Bancroft, C., 1991. Mediation by calcium of thyrotropin--releasing hormone action on the prolactin promoter via transcription factor pit-1. Mol. Endocrinol. 5, 14881497.

Yan, G.Z., Pan, W.T., Bancroft, C., 1991. Thyrotropin-releasing hormone action on the prolactin promoter is mediated by the POU protein pit-1. Mol. Endocrinol. 5, 535-541.

Yang, B.-Y., Greene, M., Chen, T.T., 1999. Early embryonic expression of the growth hormone family protein genes in the developing rainbow trout, Oncorhynchus mykiss. Mol. Reprod. Dev. 53, 127-134.

Yang, Z., Nielsen, R., Goldman, N, Pedersen, A.M., 2000. Codon-substitution models for heterogeneous selection pressure at amino acid sites. Genetics 155, 431-449

Zhang, W., Tian, J., Zhang, L., Zhang, Y., Li, X., Lin, H., 2004. cDNA sequence and spatiotemporal expression of prolactin in the orange-spotted grouper, Epinephelus coioides. Gen. Comp. Endocrinol. 136, 134-142. 
Figure legends

Fig. 1. Structure of the prl gene of the sea bream Sparus aurata (AJ509807). Primers used for D. labrax prl gene amplification are represented by arrows and their sequences were determined according to GenBank cDNA PRL sequence of sea bass (X78723). Exons are represented by open boxes and intron by black lines.

Fig. 2. Nucleotide sequence of the PRL gene of Dicentrarchus labrax. Coding regions are in upper cases and non-coding regions are in lower cases. The corresponding amino-acid sequences are indicated in bold characters. The identified TATA box is boxed, and the Pit-1 binding site is in grey.

Fig. 3. Neighbor-Joining tree (Saitou and Nei, 1987) based on coding regions of PRL gene in teleosts. Deletion of the peptide signal sequence did not change tree topology (not shown). Bootstrap values are indicated for each node. Taxonomic groups are indicated on the right. Data are from Genbank (accession number given in the text), except for Dicentrarchus labrax 2. The other available sequence for D. labrax is from Doliana et al. (1994, [X78723]). The observed difference between sea bass sequences is not due to last portion of exon $\mathrm{V}$ (see text and Table 2).

Fig. 4. Relative expression of PRL in gills (A) and intestine (B) of sea bass ( $n=5$ for each condition) obtained by using semi-quantitative RT-PCR. Results are presented as the mean ratio OD PRL / OD 28S. The five conditions tested are sea bass experimentally acclimated to seawater (SW) or freshwater (FW), unsuccessfuly acclimated to freshwater (UF) and from the wild (Mediterranean Sea [Sea] and Ingril lagoon [Lag]). Letters indicate significant differences of PRL expression among the various groups. 
$1 \quad$ Table 1

2 Sequences of primers used to amplify PRL gene in the sea bass, Dicentrarchus labrax.

\begin{tabular}{ll}
\hline Primer name & Primer sequence \\
\hline PRL 1 & Sense (F) ATGGCTCAGAGGAAAACCAATGGAAGC \\
& Antisense (R) GCTTCCATTGGTTTTCCTCTGAGCCAT \\
PRL 2 & Sense (F) CCCATCTCTGACCTGCTCGACCGAGCCTC \\
& Antisense (R) GAGGCTCGGTCGAGCAGGTCAGAGATGGG \\
PRL 3 & Sense (F) CGCCCATTGACAAGGAGCAAGCTCTGC \\
& Antisense (R) GCAGAGCTTGCTCCTTGTCAATGGGCG \\
PRL 4 & Sense (F) GTTCGCTCCCTGCTCCAAGCCTGGCGAGA \\
& Antisense (R) TCTCGCCAGGCTTGGAGCAGGGAGCGAAC \\
PRL 5 & Antisense (R) TCCGCTGCCGGGCAGCAAAATTGCAACC
\end{tabular}


Table 2

Organisation of the PRL gene in teleosts (length in base pairs). Except for the sea bass (this study), data are from GenBank (accession numbers are given in the text).

\begin{tabular}{|c|c|c|c|c|c|c|c|c|c|c|}
\hline & Exon I & Intron 1 & Exon II & Intron 2 & Exon III & Intron 3 & Exon IV & Intron 4 & Exon V & $\begin{array}{l}\text { Total } \\
\text { length }\end{array}$ \\
\hline Sea bass, $D$. labrax & 43 & 448 & 113 & 483 & 108 & 860 & 183 & 120 & $179 *$ & $2537^{\#}$ \\
\hline Sea bream, S. aurata & 42 & 718 & 112 & 390 & 108 & 980 & 182 & 148 & 190 & 2870 \\
\hline Mozambique tilapia, O. mossambicus & 42 & 1022 & 112 & 362 & 107 & 700 & 182 & 118 & 183 & 2828 \\
\hline Channel catfish, I. punctatus & 39 & 604 & 121 & 793 & 104 & 124 & 182 & 530 & 188 & 2685 \\
\hline Common carp, C. carpio & 30 & 117 & 121 & 137 & 107 & 992 & 182 & 136 & 190 & 2012 \\
\hline
\end{tabular}

* Length of exon V is underestimated because of design of primer PRL 5R within this exon (Fig. 1). Based on comparison with GenBank sequence (X78723; Doliana et al., 1994), exon V should be 189 bp long. Then, the total length of gene would be 2547 bp.

\# Underestimated value, see quotation above. 


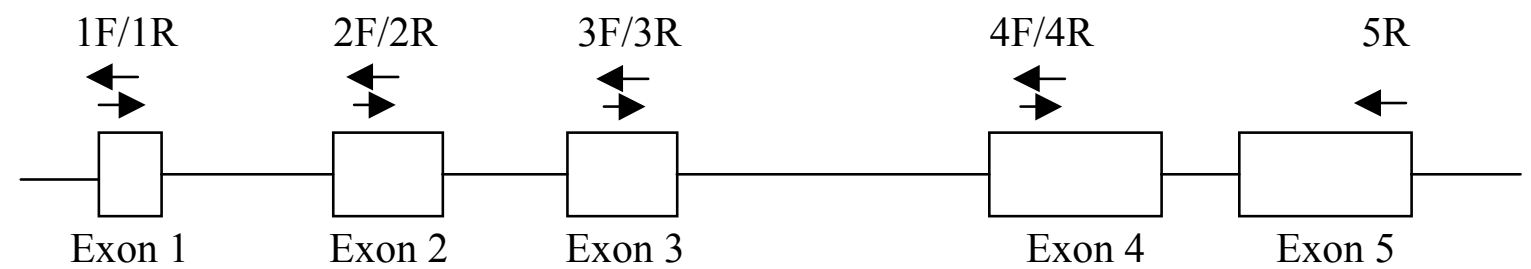

Figure 1 
acaaaacattgtgcaaacatccgtgtyttattcatccatcttattaagatcctggagggggcttttccata accgtgccacacacgcactcaatcatcaacctgttgcatccattcaaatctccttaaccatgtttctcatt atgagttcagttcagcatactgcataaccaaagtgctgaagtcaaggaactataaaatggaggcaacatsss tgaaagagaaagaaacagbcagcgaggcaaaaggaagcaaaggctaacaaatagcaacagaagagag ATG $\begin{array}{lllllllllllll}\mathbf{A} & \mathbf{Q} & \mathbf{R} & \mathbf{K} & \mathbf{T} & \mathbf{N} & \mathbf{G} & \mathbf{S} & \mathbf{K} & \mathbf{L} & \mathbf{F} & \mathbf{M} & \mathbf{M}\end{array}$ GCT CAG AGG AAA ACC AAT GGA AGC AAA CTC TTC ATG ATG G gtgagatgagctttgatc aatctccgaaagtatttgaaaatgtgaaattatttgcatctgtctgtatggaatctaaacaatgctgtgttt tttaat ttaaaatactgatatcagcctcaaaatccagtattggcgggatact taccat taaaaacttt gcatttccgcttttttatccaacaaaattcagtgattgattcattaatcatcattcattaaatccttcagaa aacat tcaatgttgtgaaaaggggtataaaagatactggaatatcatgctgcgttaatatcaggttggaaat ctgttgcatttgctggttaggcaacagttaacagctagcctatcctgaccagcggatgtggatctgaaaagc ccattgaaaaactgtatgtgacatgtggctttacgatgtgtatcatccgtcatatttccgtgctccccagTG $\begin{array}{llllllllllllllllll}\mathbf{L} & \mathbf{Y} & \mathbf{M} & \mathbf{V} & \mathbf{A} & \mathbf{A} & \mathbf{C} & \mathbf{S} & \mathbf{A} & \mathbf{I} & \mathbf{P} & \mathbf{I} & \mathbf{S} & \mathbf{D} & \mathbf{L} & \mathbf{L} & \mathbf{D} & \mathbf{R}\end{array}$ TTG TAC ATG GTG GCA GCG TGC AGT GCC ATC CCC ATC TCT GAC CTG CTC GAC CGA $\begin{array}{llllllllllllllllll}\mathbf{A} & \mathbf{S} & \mathbf{Q} & \mathbf{R} & \mathbf{S} & \mathbf{D} & \mathbf{T} & \mathbf{L} & \mathbf{H} & \mathbf{S} & \mathbf{L} & \mathbf{S} & \mathbf{T} & \mathbf{T} & \mathbf{L} & \mathbf{T} & \mathbf{Q} & \mathbf{D}\end{array}$ GCC TCC CAG CGC TCT GAC ACA CTG CAC TCC CTC AGC ACG ACG CTC ACC CAG GAC $\mathbf{L}$

CTG gtcagttttgtgtgtgtgtttgcactgtcaggaggtatctgagccttccctaacatacatgctaaac ctcaggttaaagccatatttgatgtgctctcagcttcctgatggggtctgaatggagtaggggatattcgg accccgttgtctagttctgtcatgtattcagcatagtgggaataaaatactacatgggatgaaagattggtt aacatctttaccttaaaggtccagtttgtaacatttaggatgatccattggcagaaattgaatatgtttc atgtgtgtataataaaaatggttgtgtttttgtgaccttagaatgagttgtttttagctacaggacaaggga cattaatgttacttttaactctttacatttccaaccttccaggtagtttctgttaatttgtgtattaaca tgcagaattttaaaactttccatcacaatgtaaaatcacgctctgtccettccagGAC TCT CAT TTC $\begin{array}{llllllllllllllllll}\mathbf{P} & \mathbf{P} & \mathbf{M} & \mathbf{G} & \mathbf{R} & \mathbf{V} & \mathbf{I} & \mathbf{M} & \mathbf{P} & \mathbf{R} & \mathbf{P} & \mathbf{S} & \mathbf{M} & \mathbf{C} & \mathbf{H} & \mathbf{T} & \mathbf{S} & \mathbf{S}\end{array}$ CCT CCG ATG GGC CGG GTG ATC ATG CCC CGC CCT TCA ATG TGC CAC ACC TCC TCT $\begin{array}{llllllllllllll}\mathbf{L} & \mathbf{H} & \mathbf{T} & \mathbf{P} & \mathbf{I} & \mathbf{D} & \mathbf{K} & \mathbf{E} & \mathbf{Q} & \mathbf{A} & \mathbf{L} & \mathbf{Q} & \mathbf{V} & \mathbf{S}\end{array}$

CTA CAT ACG CCC ATT GAC AAG GAG CAA GCT CTG CAA GTA TCA gtaagtgatcagggg cgaagtactgagggggttacatgggcgctggaagtaggggtgctgagggggctttcttctttttttgtact ggggtttacatt tatacaaattttgcagagttttatccactaaaaagtaataaratgtttgkragatttaaa catt taaattaaataggctataaattatgctgtccattgaratgaatgaraacatcatgaatgtcatgcatt tagcatttagtgtgacttcattgtgtagactgactttcagcaactctgactgcctttcagcatccctaaata ctagaatgaatggctgtggatgcggggaggggcacattgaggaaacctacagggtccataattttgtgctac acccctaactgtcattcatcagattgtagataatragtttgagtcagatgtctgartattatattrctgar aacataagctcatcccacaattgaaaggttttgccatcactgatgcactgatcaccttgtgatatactcgag acttgagtgaaggttctatgagtacaaacattaatgagctatcatagctttcacccaaataattaagtgaac attgtagcaatt tgcaaccgagccacaagccacatt gatt taaaggtccagtgtgtaacatt aggaggat ctattgtcagaaatagaatataatattcatagctatgtyyttattaatgtataatcacctgaatgtatgaat tgttgtgttcatcaccttacttcagctttttctgtattcatatcatatcattttgatctcttgtcttccaa E A D $\quad \mathbf{L} \quad \mathbf{L}$

ttaatcttcagcttattgtatyatttatattatctgtctggcttcttctccagGAG GCA GAC CTG TTG

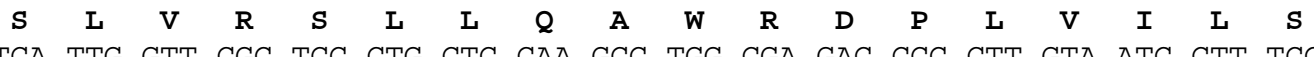
$\begin{array}{llllllllllllllllll}\mathbf{T} & \mathbf{S} & \mathbf{A} & \mathbf{N} & \mathbf{T} & \mathbf{L} & \mathbf{P} & \mathbf{H} & \mathbf{P} & \mathbf{A} & \mathbf{Q} & \mathbf{N} & \mathbf{S} & \mathbf{I} & \mathbf{S} & \mathbf{T} & \mathbf{K} & \mathbf{V}\end{array}$ ACC TCT GCT AAC ACC TTA CCT CAC CCG GCC CAA AAC AGC ATA TCC ACC AAA GTC $\begin{array}{llllllllllllllllll}\mathbf{Q} & \mathbf{E} & \mathbf{L} & \mathbf{L} & \mathbf{E} & \mathbf{H} & \mathbf{T} & \mathbf{K} & \mathbf{S} & \mathbf{L} & \mathbf{G} & \mathbf{D} & \mathbf{G} & \mathbf{L} & \mathbf{D} & \mathbf{I} & \mathbf{L} & \mathbf{S}\end{array}$ CAG GAG CTG CTG GAG CAT ACC AAA AGC CTG GGA GAT GGC CTG GAT ATC TTA TCT G $\quad K$

GGC AAG gtgtgtgagtacagaaagacaaaccctcgtttggcactcatttaaaacattaatttaaaatg F G P A 153

tctttcttctctttccoggccetccetccaccttccetgcttcctttctctcccagTTT GGT CCA GCA 2652

$\begin{array}{lllllllllllllllllll}\text { A } & \mathbf{Q} & \mathbf{S} & \mathbf{I} & \mathbf{S} & \mathbf{S} & \mathbf{L} & \mathbf{P} & \mathbf{Y} & \mathbf{R} & \mathbf{G} & \mathbf{G} & \mathbf{N} & \mathbf{D} & \mathbf{I} & \mathbf{S} & \mathbf{Q} & \mathbf{D} & 171\end{array}$ GCT CAG TCC ATC TCC TCA CTG CCC TAC AGA GGA GGC AAT GAC ATC AGC CAG GAC 2706 $\begin{array}{lllllllllllllllllll}\mathbf{R} & \mathbf{I} & \mathbf{S} & \mathbf{R} & \mathbf{L} & \mathbf{T} & \mathbf{D} & \mathbf{F} & \mathbf{H} & \mathbf{F} & \mathbf{L} & \mathbf{M} & \mathbf{S} & \mathbf{C} & \mathbf{F} & \mathbf{R} & \mathbf{R} & \mathbf{D} & 189\end{array}$ AGG ATT TCC AGA CTA ACC GAC TTC CAC TTC TTG ATG TCC TGC TTC CGC CGG GAC 2760

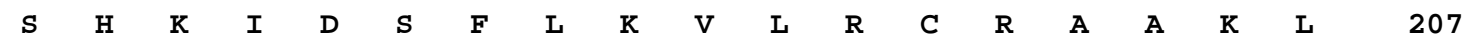
TCC CAC AAG ATT GAC AGC TTC CTG AAG GTC CTC CGC TGC CGG GCA GCA AAA TTG 2814 $\mathbf{Q}$ CAA CC

Fig. 2. 


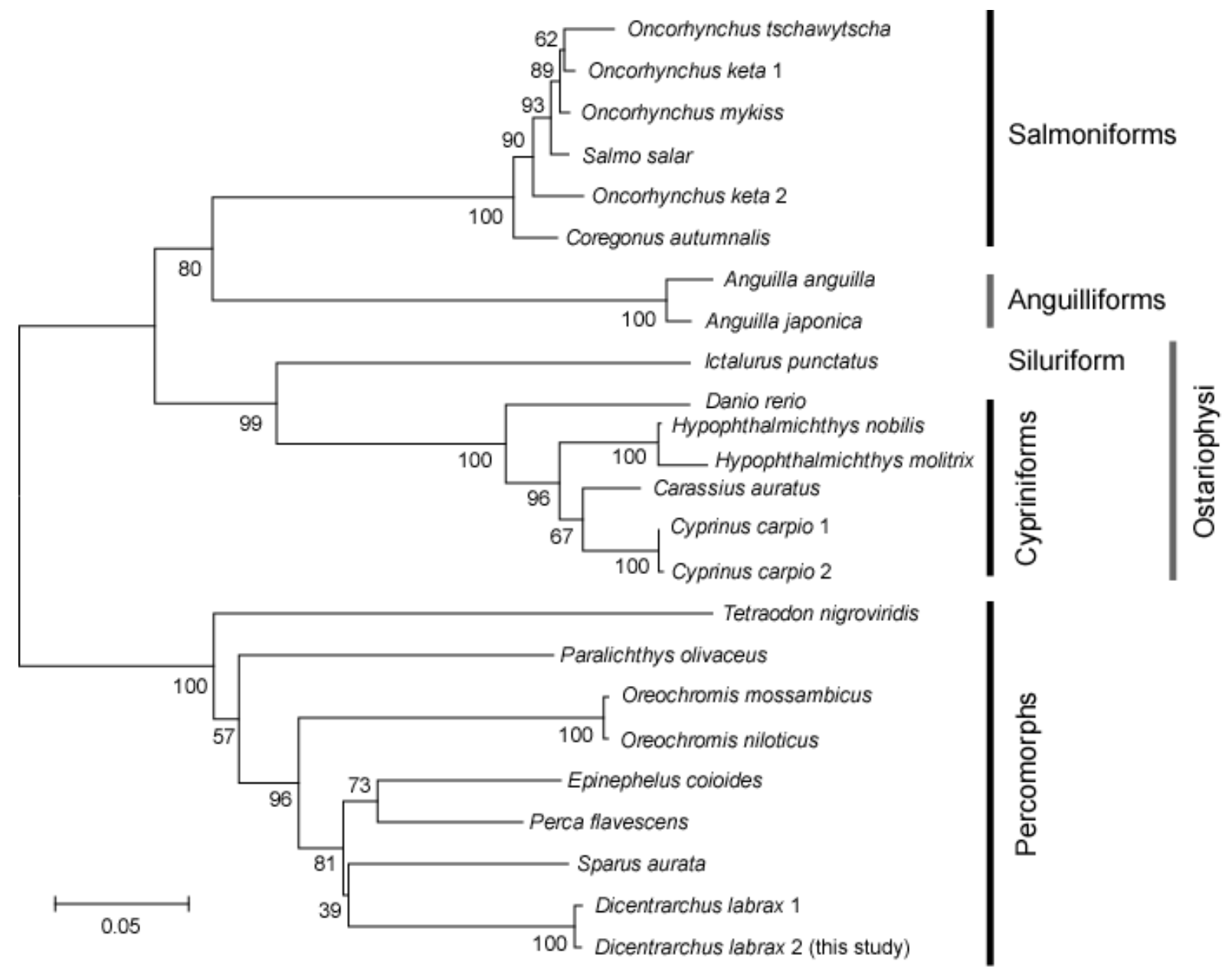

Figure 3 

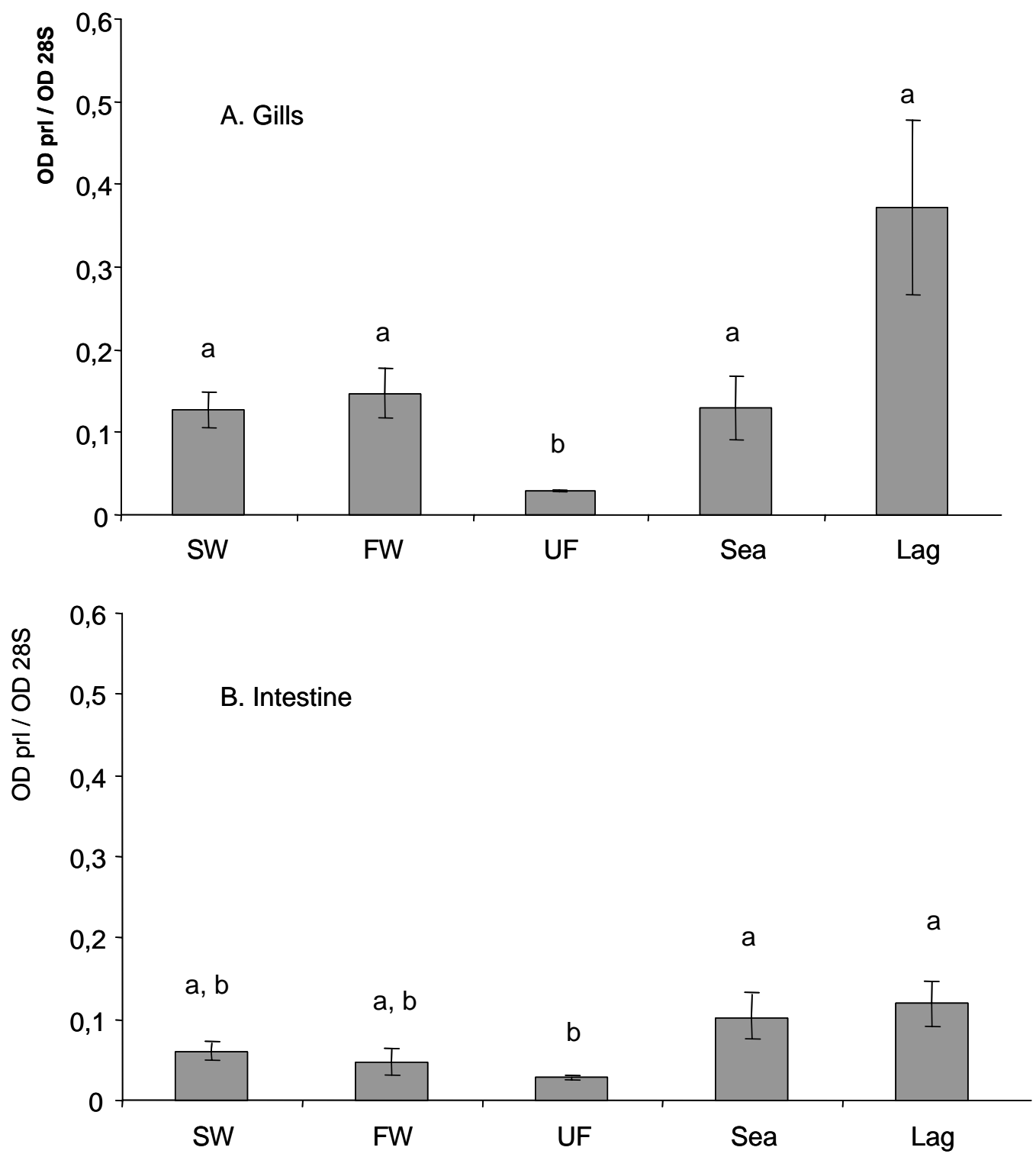

Figure 4 